\title{
Die Structural Design Features Based On the AD
}

\author{
Kaijing Zhou \\ Tianjin Engineering Center of Digital Manufacturing of Die \& Mold, Tianjin University of Technology and Education No.1310, \\ Dagu South Road, Hexi District, Tianjin 300222, China
}

\begin{abstract}
User demands for the die is the function. Actually, a user to buy the mold is the function of mold rather than the mold itself. Then, it needs to be abstract the functional requirements and transform into actual mold structure. With the help of AD to solve the problem of functional decomposition and structure solution, and an example for the carriage dies structure design.
\end{abstract}

Keywords: AD, stamping die, the functional of the structure, design.

\section{AD in the "s" word map}

Axiomatic design MIT, a design decision method, was proposed by professor Suh in the middle of 1970s. Axiomatic design is different from other design methods, it needs to take full account of the relationship between the two domains, and then complete the final product design.

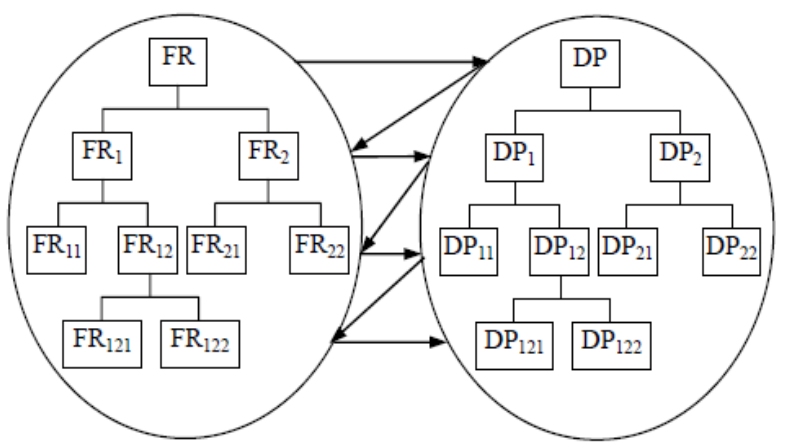

Figure 1: word die structure design of the mapping structure diagram

\section{Die Functional Decomposition}

\subsection{Functional Decomposition Tree}

To achieve the conversion of functional structure, first of all, functional decomposition is need to be done. Analysis of the demand to obtain total functionality of the system. Under normal circumstances, you need to devised function into multiple simple, relatively easy to achieve sub-functions, from sub-functions start to achieve sub-function principle structure, then combination it reasonable and orderly, you can get the final structure of die system design. A functional decomposition product always begins with function, with the help of total functional decomposition tree to division it into the sub-function or functional elements. The results of the decomposition as shown in Figure 2.

\subsection{Based on TRIZ law of completeness of the functional}

Decomposition of the die structure design is the actual form of moulds, and demand function is the abstraction of user needs, so in the design of die structure needs will take the user demand as constraint, with the analysis of general user demand, expressed as Cs, and structural DPS demands with the functional requirements of FRS and constraints requirements CS to express. According to the function decomposition of die structure, the stamping die function has the same six functions in the decomposition, so the law of completeness in the TRIZ technology system evolution law is adopted, According to the requirement of function (FRs), the user demands can be abstracted by the stamping die structure as the functional requirement $\left(\mathrm{FR}_{0}\right)$ : A variety of molding functions, and its decomposition, Decomposition into process forming function $\left(\mathrm{FR}_{1}\right), \mathrm{FR}_{2}$ Forming function for auxiliary. According to TRIZ theory, a complete technical system has to include four functions: power device, transmission device, actuator and control device. And for stamping die can be a variety of molding functions in accordance with the law of the completeness of $\mathrm{FR}_{1}, \mathrm{FR}_{2}$ to make further decomposition to decompose, constitute a complete mold system. Take these two functions into $\mathrm{FR}_{11}$ as work function, $\mathrm{FR}_{12}$ as the function orientation and $\mathrm{FR}_{13}$ for loading and unloading material ejection function decomposition, $\mathrm{FR}_{21}$ as guiding function and $\mathrm{FR}_{22}$ as support clip to function, $\mathrm{FR}_{23}$ as fastening function, and continue down decomposition, the decomposition until not so far. The decomposition process is shown in figure3.

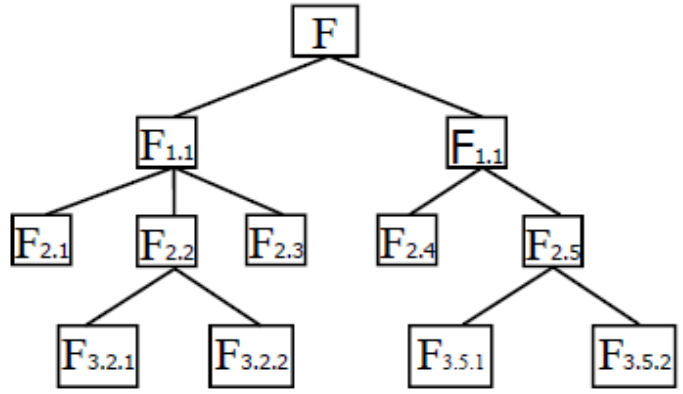

Figure 2: Functional decomposition

\section{Function structure design of stamping die}

\subsection{Decomposition of stamping die structure}

Based on AD theory, in order to realize the transformation from function to structure the structures corresponding to function are expressed. So it is necessary to structure of the stamping die is decomposed as shown in figure 3-1. For stamping die, according to their different functions in general can be divided into the following several parts: molding parts, positioning parts unloading pushing parts, guiding parts, bearing and fixed components. Mold of the main for molding parts and positioning parts and unloading unloading components, we generally referred to process components; 


\section{International Journal of Science and Research (IJSR) \\ ISSN (Online): 2319-7064 \\ Index Copernicus Value (2013): 6.14 | Impact Factor (2014): 5.611}

and other components is only an auxiliary mold to complete the work, so called auxiliary components, and each component specific decomposition as a functional element corresponding to the structure element, concrete structure decomposition is shown in Figure4.

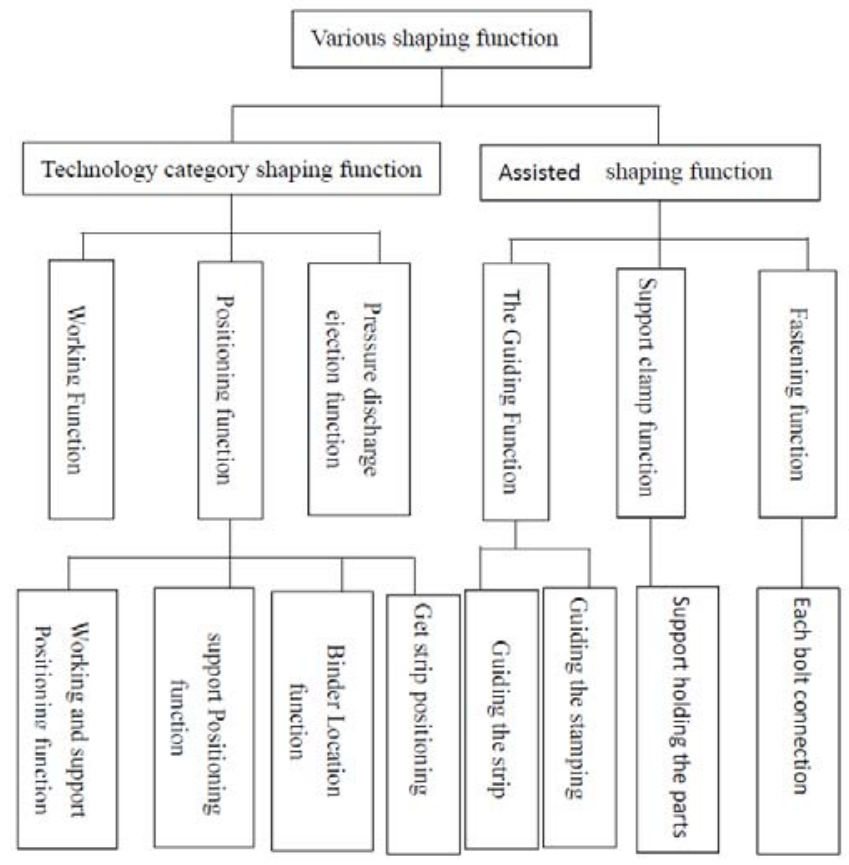

Figure 3: Stamping die completeness of functional decomposition tree

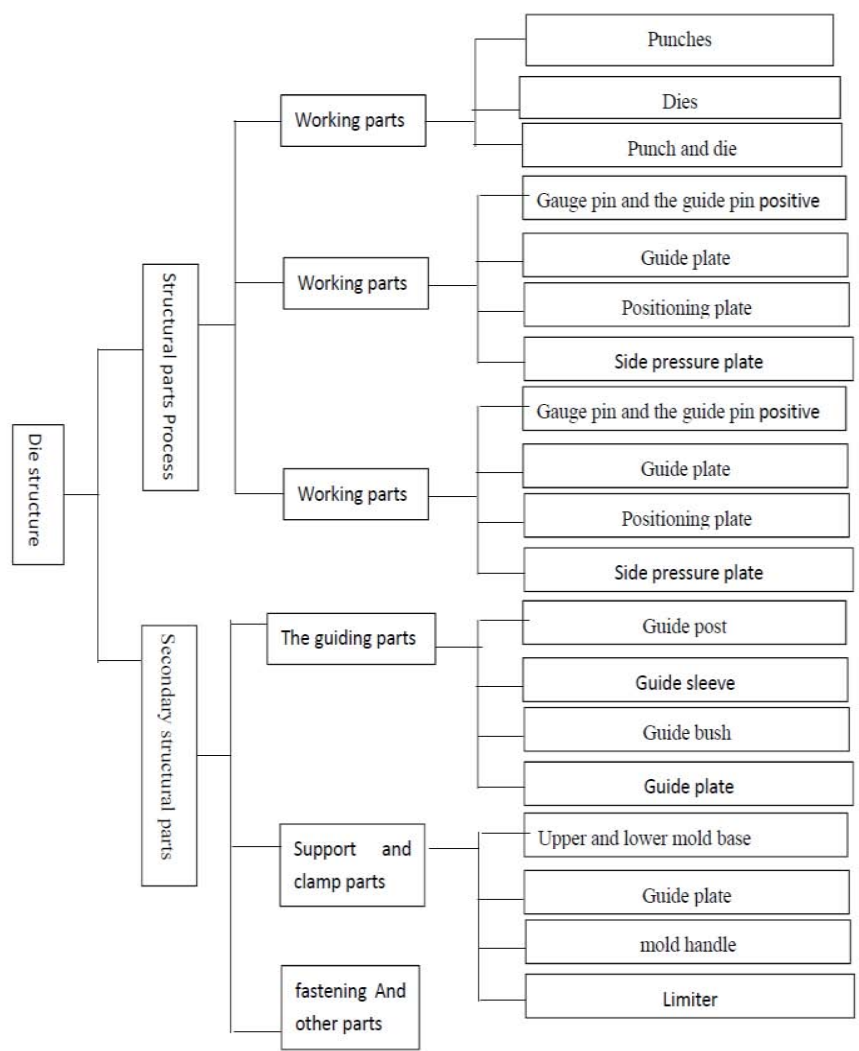

Figure 4: Die Breakdown Structure

\subsection{Structure Selection}

According to the requirement of Cs: The die structure design of User demand partial constraint or Constraint between systems conduct as the boundary of the design. combined with the characteristics of die structure, The structure may be one or more of the structural elements of the last one, which is determined by the demand. Therefore, at this stage can be lead into Mold user requirements Cs, As a design parameter DPs selection of the basic constraints, which can be decomposed as follows: $C_{1}$, good reliability, $C_{2}$ simple structure, $C_{3}$ high efficiency, $C_{4}$ low cost, $C_{5}$ good operability, $C_{6}$ convenient disassembly and maintenance. But the selection of the die structure is determined by features of product parts. Outstanding demand as a function of the key parts of constraints, here mainly refers to the precision requirement: $C_{7}$ no precision and $C_{8}$ accuracy requirements. According to the word mapping, there is a mapping relationship between design parameters DPs and function FRs, which will be affected by the constraints of the Cs, So the parameters can be designed to be more reasonable and meet the needs of users.

According to the structural characteristics of the stamping die, for the function of FR, provided by a number of design parameters DP, and under the influence of the constraint conditions Cs, selected the reasonable design parameters. Its DP according to FRs and Cs select the appropriate DPs method as shown:

1 The choice of the assembly structure

(1) no accuracy requirement

\begin{tabular}{|c|c|c|}
\hline $\begin{array}{c}\text { Function } \\
\text { (FRs) }\end{array}$ & constraint (Cs) & structure (DPs) \\
\hline $\begin{array}{l}F R_{1} \text { the } \\
\text { function of } \\
\text { molding } \\
\text { technology }\end{array}$ & $\begin{array}{c}C_{1} \text { Good reliability } \\
C_{2} \text { Simple structure } \\
C_{3} \text { High efficiency } \\
C_{4} \text { low cost } \\
C_{5} \text { Good maneuverability }\end{array}$ & $\begin{array}{c}D P_{11} \text { working parts } \\
D P_{12} \text { Positioning } \\
\text { parts } \\
D P_{13} \text { Pressure, } \\
\text { discharge, pushing } \\
\text { parts } \\
\end{array}$ \\
\hline $\begin{array}{c}F R_{2} \\
\text { Assisted } \\
\text { molding } \\
\text { function }\end{array}$ & $\begin{array}{c}C_{6} \text { Disassembly easy } \\
\text { maintenance }\end{array}$ & $\begin{array}{c}D P_{22} \text { Support, } \\
\text { clamping parts } \\
D P_{23} \text { Fastening parts }\end{array}$ \\
\hline
\end{tabular}

(2) Accuracy Requirements

\begin{tabular}{|c|c|c|}
\hline (FRs) & Cs & DPs \\
\hline $\begin{array}{l}F R_{1} \text { the } \\
\text { function of } \\
\text { molding } \\
\text { technology }\end{array}$ & $\begin{array}{l}C_{1} \text { Good reliability } \\
C_{2} \text { Simple structure } \\
C_{3} \text { High efficiency } \\
C_{4} \text { low cost } \\
C_{5} \text { Good } \\
\text { maneuverability }\end{array}$ & $\begin{array}{lr}D P_{11} & \text { Working part } \\
D P_{12} & \text { Positioning } \\
\text { parts } & \\
D P_{13} & \text { Pressure, } \\
\text { discharge, } & \text { pushing } \\
\text { parts } & \end{array}$ \\
\hline $\begin{array}{l}\text { the function } \\
\text { of Assistting } \\
\text { molding }\end{array}$ & $\begin{array}{l}C_{6} \text { Disassembly easy } \\
\text { maintenance }\end{array}$ & \begin{tabular}{|ll}
$D P_{22}$ & Support, \\
clamping & parts \\
$D P_{23}$ & Fastening \\
parts & \\
$D P_{21}$ & Guiding \\
parts &
\end{tabular} \\
\hline
\end{tabular}


(2)The choice of components

1) The choice of Design parameters $D P_{12}$

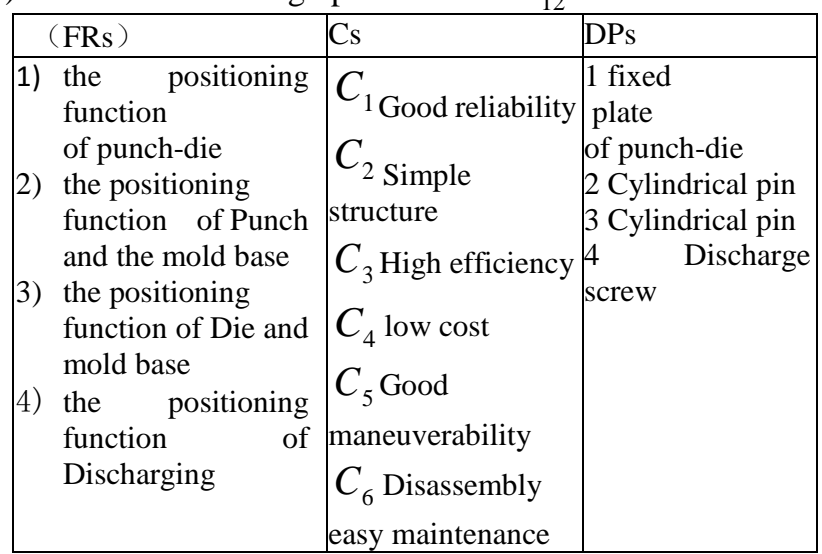

2) The choice of Design parameters $D P_{13}$

\begin{tabular}{|c|c|c|c|}
\hline & FRs & Cs & DPs \\
\hline 1 & $\begin{array}{l}\text { Guide } \\
\text { function } \\
\text { of imported } \\
\text { materials }\end{array}$ & $\begin{array}{l}C_{1 \text { Good reliability }} \\
C_{2} \text { Simple structure } \\
C_{3} \text { High efficiency }\end{array}$ & stop pin \\
\hline 2 & $\begin{array}{l}\text { Guide } \\
\text { function of } \\
\text { pressing }\end{array}$ & $\begin{array}{c}C_{4} \text { low cost } \\
C_{5} \text { Good maneuverability } \\
C_{6} \text { Disassembly easy } \\
\text { maintenance }\end{array}$ & $\begin{array}{c}\text { model } \\
\text { set }\end{array}$ \\
\hline
\end{tabular}

\section{Conclusion}

$\mathrm{AD}$ by means of the word mapping process in user demand constraint functions to achieve a die structure design, using this method can achieve faster structural design features die.

\section{References}

[1] Axiomatic study, Ying Su, Yu Ming, Zhang Bopeng configuration information based on Quality Function [J] Computer Integrated Manufacturing Systems, 2002 (10):. P829-P834.

[2] G.S.Altshuller. The Innovation Algorithm, TRIZ, systematic innovation and technical creativity[M], Technical Innovation Center, INC, Worcester, 1999

[3] J.Malaqvist. Improved Function-means Trees by Inclusion of Design History Information. Journal of Engineering Design, 1997, 18(2): p107 117

[4] C.T.Hansen. An Approach to Simultaneous Synthesis and Optimization of Composite Mechanical Systems. Journal of Engineering Design， 1995， 6(3): p249 265 